\title{
SISTEM MONITORING KUALITAS AIR KOLAM BUDIDAYA MENGGUNAKAN JARINGAN SENSOR NIRKABEL BERBASIS PROTOKOL LORA
}

\author{
Adhitya Bhawiyuga ${ }^{1}$, Widhi Yahya ${ }^{2}$ \\ 1,2Fakultas Ilmu Komputer, Universitas Brawijaya

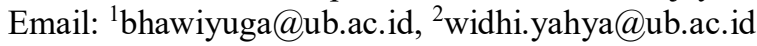

(Naskah masuk: 26 November 2018, diterima untuk diterbitkan: 07 Januari 2019)

\begin{abstract}
Abstrak
Salah satu faktor penting yang berpengaruh terhadap kesuksesan perikanan budidaya adalah aspek kualitas air kolam yang tergambar pada beberapa parameter fisik antara lain suhu, derajat keasaman $(\mathrm{pH})$, oksigen terlarut maupun kekeruhan air. Sebagai tempat hidup ikan, perubahan parameter fisik tersebut dapat berpengaruh secara langsung terhadap pertumbuhan dan daya tahan ikan budidaya. Oleh karena itu, peternak perlu melakukan pengamatan berkala terhadap kondisi air kolam budidaya untuk kemudian memberikan perlakuan tertentu agar kondisi air tetap sesuai dengan prasyarat tumbuh kembang ikan yang dibudidayakan. Peternak ikan dapat melakukan pengamatan kondisi air dengan mengambil sampel air kolam untuk kemudian diamati di laboratorium atau menggunakan peralatan sensor. Mekanisme tersebut memerlukan kehadiran peternak secara periodik pada kolam budidaya. Hal ini tentu dapat menyulitkan peternak apalagi jika ukuran kolam budidaya cukup luas. Lebih jauh lagi, kondisi fisik air dapat berubah dalam waktu yang relatif cepat, terutama karena adanya polutan baik polutan eksternal maupun internal. Pada penelitian ini dibangun sebuah sistem pemantauan kualitas air kolam budidaya ikan secara real time menggunakan jaringan sensor nirkabel. Sistem yang diusulkan terdiri atas tiga bagian, yaitu : kumpulan perangkat node sensor, perangkat gateway dan data center. Secara periodik perangkat node sensor mengukur parameter fisik air menggunakan sensor dan mengirimkannya ke perangkat gateway. Perangkat gateway kemudian mengirimkan data tersebut ke data center untuk kemudian disimpan dan diolah. Peternak dapat mengamati kondisi air kolam budidaya secara real time dari sebuah aplikasi berbasis web. Untuk melakukan validasi terhadap sistem yang dibangun, pengujian fungsionalitas dan kinerja dilakukan. Hasilnya menunjukkan bahwa sistem mampu merespons perubahan pada kondisi air seperti, tingkat kejernihan, $\mathrm{pH}, \mathrm{O}_{2}$ terlarut dan temperatur. Sedangkan pada pengujian kinerja diperoleh hasil terbaik pada jarak 40 meter dengan besar paket 82 byte yang memberikan nilai hasil pengujian sebesar 189,4ms untuk delay dan 7,8\% packetloss.
\end{abstract}

\section{AQUACULTURE WATER MONITORING SYSTEM USING WIRELESS SENSOR NETWORK WITH THE LORA COMMUNICATION PROTOCOL}

\begin{abstract}
The water physical condition including water temperature, acidity level $(\mathrm{pH})$ and dissolved oxygen level play an important role in the success of aquaculture. As the habitat of the fish, the changes of physical parameter in water gives a direct impact to the growth and vitality of the fish. Therefore, fish farmer needs to periodically observe that water condition and takes an immediate action upon any changes. At present, the fish farmer can perform a water monitoring by taking a water sample and observe it in laboratory. However, this method can be inefficient since the water condition can be changed rapidly due to the polutant intervention either from external or internal. Therefore, in this paper, we propose a real time aquaculture water monitoring system using wireless sensor network. The proposed system can be composed into three main components : node sensors, gateway device and data center. Periodically, each node sensor measure the physical parameter of water using its sensing device and send those data to the gateway using LoRa communication module. The gateway then relays the sensor data to the datacenter using Restful Webservice protocol. Based on the functional evaluation the proposed system can give the proper response on the changes of the water quality in term of turbidity, acidity level, dissolved oxygen and temperature. Furthermore, from the network performance testing, we observe that the delay is 189.4ms and the packetloss is $7.8 \%$.
\end{abstract}

Keywords: WSN, water quality, aquaculture, LoRa 


\section{PENDAHULUAN}

Perikanan budidaya merupakan salah satu sektor potensial yang dapat dikembangkan untuk meningkatkan kesejahteraan masyarakat. Di Indonesia, terdapat beberapa jenis ikan yang populer dibudidayakan antara lain udang, bandeng, lele, patin, nila dan kerapu. Berdasarkan data yang dirilis oleh Direktorat Jenderal Perikanan Budidaya tahun 2016, tingkat konsumsi ikan naik dari 40,9 kg/kapita/tahun pada tahun 2015 menjadi 43,88 kg/kapita/tahun pada tahun 2016. Pada tahun 2019, angka ini diproyeksikan naik menjadi 54,49 kg/kapita/tahun.

Dari sisi potensi penyerapan tenaga kerja, sektor perikanan budidaya pada tahun 2030 diproyeksikan dapat menciptakan 8,9 juta lapangan kerja baru yang meningkat dari angka saat ini yaitu 2,7 juta lapangan kerja (Philips, 2015). Sayangnya, walaupun punya potensi yang cukup besar, namun, sektor perikanan budidaya masih belum tergarap dengan baik. Hal ini ditunjukkan dengan penurunan angka PDB perikanan dari $8,37 \%$ pada tahun 2015 menjadi 5,15\% pada tahun 2016 (Ditjen Perikanan Budidaya, 2017). Kondisi lingkungan dan sosio-ekonomi pasar dapat berkontribusi terhadap peningkatan dan penurunan kapasitas produksi tersebut.

Salah satu faktor penting yang berpengaruh terhadap kesuksesan perikanan budidaya adalah kualitas air. Beberapa parameter fisik yang dapat diamati untuk menggambarkan kualitas air antara lain adalah suhu, derajat keasaman $(\mathrm{pH})$, oksigen terlarut maupun kekeruhan air (Minggawati, 2012). Sebagai tempat hidup ikan, perubahan parameter fisik tersebut dapat berpengaruh secara langsung terhadap pertumbuhan dan daya tahan ikan budidaya. Setiap jenis ikan budidaya memiliki prasyarat kondisi air yang berbeda agar dapat tumbuh secara optimal. Oleh karena itu, peternak perlu melakukan pengamatan berkala terhadap kondisi air kolam budidaya untuk kemudian memberikan perlakuan tertentu agar kondisi air tetap sesuai dengan prasyarat tumbuh kembang ikan yang dibudidayakan.

Untuk melakukan pengamatan tersebut, seorang peternak dapat mengambil sampel air kolam budidaya untuk kemudian diamati di laboratorium atau menggunakan peralatan sensor. Mekanisme tersebut memerlukan kehadiran peternak secara periodik pada kolam budidaya. Hal ini tentu dapat menyulitkan peternak apalagi jika ukuran kolam budidaya cukup luas. Lebih jauh lagi, kondisi fisik air dapat berubah dalam waktu yang relatif cepat, terutama karena adanya polutan baik polutan eksternal seperti paparan limbah dan sisa makanan maupun polutan internal seperti bangkai ikan budidaya yang mati. Jika kondisi fisik air dapat diamati dengan cepat, peternak dapat segera melakukan penanganan jika terjadi kondisi yang tidak sesuai pada air kolam. Berdasarkan permasalahan tersebut, diperlukan sebuah mekanisme pengamatan kualitas air kolam budidaya secara akurat dan real time. Di sisi lain, solusi yang ditawarkan juga harus dapat meminimalisir keterlibatan langsung peternak dalam melakukan pengamatan.

Pada penelitian ini dibangun sebuah sistem pemantauan kualitas air kolam budidaya ikan menggunakan jaringan sensor nirkabel. Sistem terdiri atas kumpulan perangkat node sensor yang ditempatkan pada kolam untuk mengamati kualitas air dan sebuah perangkat gateway untuk mengumpulkan data dan mengirimkannya ke data center. Setiap node sensor tersusun atas tiga komponen utama yaitu mikroprosesor, sensor dan modul komunikasi. Secara periodik, node sensor mengambil data pengamatan kondisi fisik air seperti keasaman air $(\mathrm{pH})$, oksigen terlarut (dissolved oxygen), suhu dan kekeruhan air dari sensor. Data hasil pengamatan tersebut kemudian dikirimkan lewat modul komunikasi ke perangkat gateway. Pada penelitian ini, peneliti memanfaatkan modul komunikasi LoRa yang mampu mendukung komunikasi jarak jauh dengan konsumsi daya rendah. Hal ini penting mengingat node sensor akan ditempatkan pada kolam ikan sehingga node tersebut harus mampu bekerja menggunakan catu daya mandiri dari baterai yang dilengkapi sel surya. Selanjutnya, perangkat gateway meneruskan data yang dikumpulkan dari semua node sensor ke sebuah data center untuk diolah dan dianalisa lebih lanjut. Peternak dapat mengamati kondisi air kolam budidaya secara real time dari sebuah aplikasi berbasis web. Selanjutnya, jika terjadi sebuah anomali, data center dapat mengirimkan sebuah notifikasi dan saran perlakuan ke peternak lewat email ataupun aplikasi.

\section{STUDI LITERATUR}

\subsection{Pengamatan Kualitas Air Kolam Budidaya Perikanan}

Pengamatan kualitas air kolam budidaya merupakan salah satu hal yang dapat dilakukan untuk meningkatkan produksi perikanan budidaya. Hal ini dapat terjadi mengingat air merupakan habitat dan tempat hidup dari ikan. Sehingga, perubahan fisik dan kimiawi yang terjadi pada air akan berpengaruh secara langsung terhadap pertumbuhan dan daya tahan ikan. Masing-masing ikan memiliki prasyarat fisik air yang berbeda. Sebagai contoh, ikan lele dapat hidup pada air yang relatif lebih keruh dengan kadar oksigen terlarut rendah jika dibandingkan dengan ikan mujair.

Pada literatur terdapat beberapa penelitian yang berhubungan dengan pemantauan kualitas air kolam budidaya baik pada media kolam maupun keramba. Minggawati, dkk melakukan penelitian untuk mengukur parameter kualitas air untuk budidaya ikan patin di karamba Sungai Kahayan (Minggawati, 2012). Beberapa parameter yang diamati antara lain suhu, kekeruhan, $\mathrm{pH}$, oksigen terlarut dan lain-lain. Mekanisme yang dilakukan adalah dengan 
mengambil sampel air untuk kemudian dianalisa di laboratorium. Pada penelitian lain, David dkk melakukan analisa prospek bisnis budidaya pembesaran ikan bandeng di Kecamatan Tugu, Kota Semarang. Dari penelitian tersebut diperoleh fakta bahwa kualitas air juga dapat mempengaruhi produktifitas peternakan bandeng.

Metode pemantauan lain dengan melibatkan teknologi jaringan sensor nirkabel diusulkan oleh Qalit dkk (Qalit, 2016). Pada sistem yang diusulkan oleh peneliti tersebut, dibangun perangkat pemantauan yang terdiri atas perangkat mikrokontroler, sensor $\mathrm{pH}$ dan suhu serta modul komunikasi Ethernet. Walaupun sudah dapat melakukan pengamatan pada kolam dengan ukuran kecil, sistem tersebut dapat menimbulkan masalah jika diterapkan pada kolam berukuran besar. Hal ini dikarenakan modul komunikasi yang dipakai adalah modul komunikasi Ethernet yang memakai kabel sebagai media komunikasinya sehingga kurang fleksibel dari sisi penempatan perangkat.

\section{METODE PENELITIAN}

Secara garis besar, terdapat beberapa langkah yang akan dilakukan pada penelitian ini untuk mencapai tujuan yang diharapkan. Langkah-langkah tersebut meliputi (i) melakukan identifikasi masalah yang dihadapi (ii) melakukan studi pustaka yang relevan dengan sistem pengamatan kualitas air kolam budidaya ikan, (iii) perancangan dan implementasi sistem, (iv) pengujian dan analisis hasil, dan (v) pengambilan kesimpulan. Pada Gambar 3.1 dapat dilihat diagram alur tahap-tahap yang akan dilakukan pada penelitian.

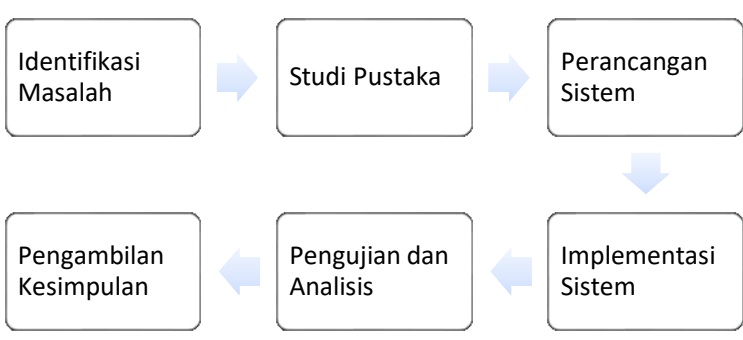

Gambar 3.1 Diagram Alur Metodologi Penelitian

\section{IDENTIFIKASI MASALAH}

Identifikasi masalah dilakukan untuk mengkaji permasalahan yang akan diselesaikan. Identifikasi masalah juga merupakan langkah untuk menemukan fitur dari sistem, sehingga sistem mampu memberikan hasil sesuai yang diinginkan. Permasalahan utama yang diangkat pada penelitian ini adalah mengenai mekanisme pengamatan kualitas air budidaya ikan secara real time dengan meminimalisir keterlibatan fisik peternak ikan. Untuk menyelesaikan permasalahan tersebut, dibutuhkan sebuah sistem pemantauan kualitas air kolam budidaya yang terdiri atas perangkat sensor yang dibekali kemampuan komunikasi untuk mengirimkan data.

Berdasarkan permasalahan yang dikaji, sistem ini harus memiliki beberapa kebutuhan fungsional diantaranya:

1. Perangkat node sensor mampu melakukan akuisisi data dari sensor pengamat kondisi fisik air dengan beberapa parameter antara lain : $\mathrm{pH}$, oksigen terlarut, kekeruhan dan suhu air.

2. Perangkat node sensor mampu mengirimkan data yang telah diakuisisi ke perangkat gateway menggunakan modul komunikasi LoRa.

3. Perangkat gateway mampu menerima data sensor dan selanjutnya meneruskan data tersebut ke pusat data menggunakan protokol Restful webservice.

4. Pusat data mampu menerima, menyimpan dan mengolah data sensor yang diperoleh dari perangkat gateway.

\section{PERANCANGAN SISTEM}

Perancangan sistem merupakan tahapan dalam merencanakan implementasi sistem berdasarkan pada kebutuhan yang telah didefinisikan pada sub Bab 4 . Arsitektur sistem yang dirancang pada penelitian ini dapat dilihat pada Gambar 5.1.

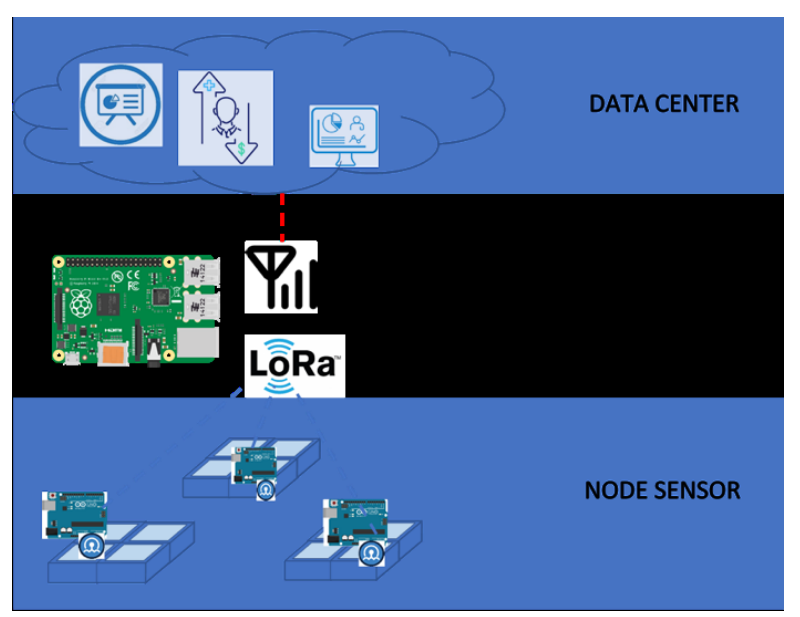

Gambar 5.1. Perancangan Arsitektur Sistem

Sistem pemantauan yang diusulkan terdiri atas tiga bagian besar yaitu : kumpulan node sensor, sebuah perangkat gateway dan pusat data. Setiap bagian memiliki alur kerja berbeda yang diilustrasikan pada Gambar 5.2.

1. Perangkat Node Sensor

Node sensor merupakan perangkat yang bertugas untuk mengamati parameter fisik dari air kolam budidaya. Perangkat jenis ini ditempatkan secara langsung pada obyek kolam yang diamati. Secara garis besar, perangkat ini tersusun atas tiga komponen, yaitu : mikroprosesor sebagai perangkat komputasi, sensor untuk mengamati parameter fisik air dan modul komunikasi untuk mengirimkan data 


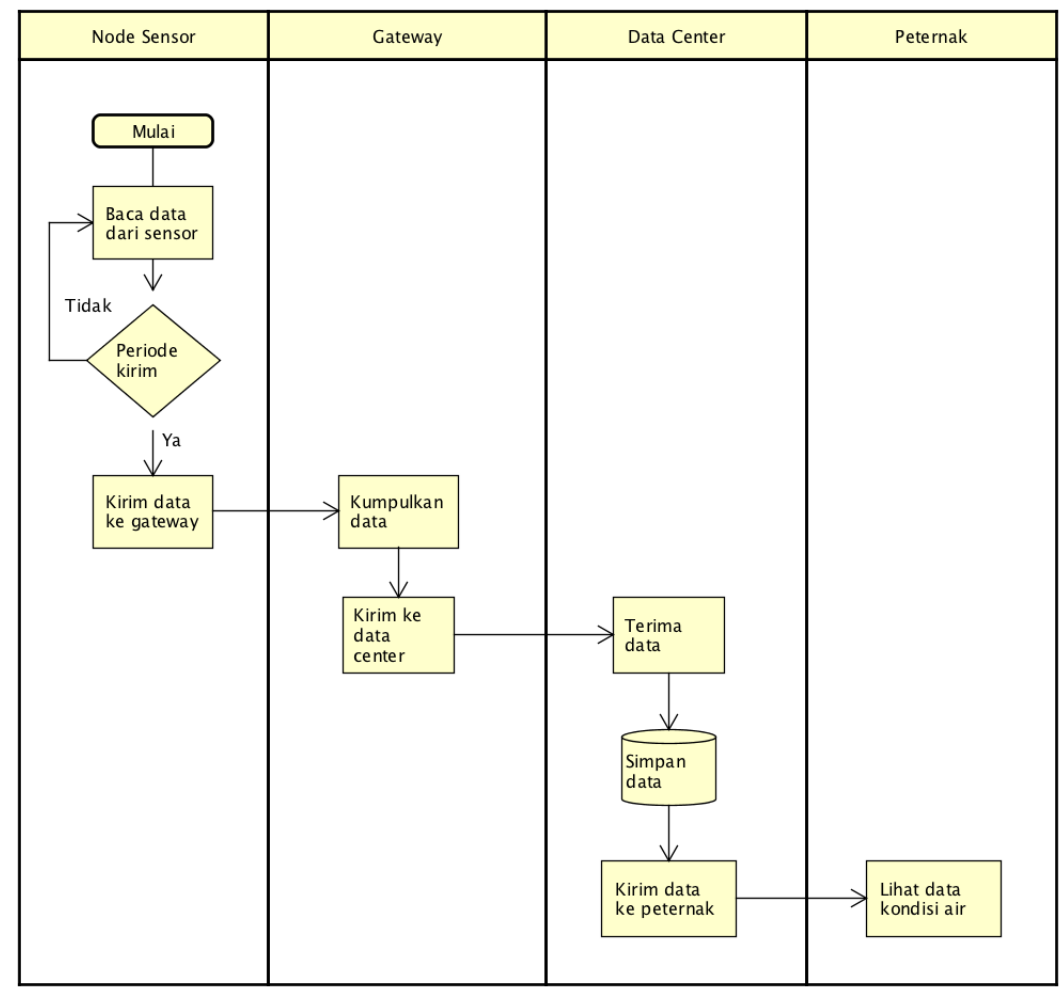

Gambar 5.2. Perancangan Alur Kerja Sistem

hasil pengamatan ke perangkat gateway. Untuk melakukan pengamatan parameter fisik air, pada penelitian ini memanfaatkan beberapa jenis komponen sensor, antara lain : sensor kadar keasaman air ( $\mathrm{pH}$ meter), sensor oksigen terlarut (dissolved oxygen), sensor suhu air, dan sensor kekeruhan air. Data hasil pengamatan selanjutnya dikirimkan ke perangkat gateway menggunakan modul komunikasi LoRa agar dapat menjangkau area kolam yang luas dengan konsumsi energi yang rendah(Rashmi, 2017).

2. Perangkat Gateway

Perangkat ini berperan untuk menerima data hasil pengamatan kondisi air kolam budidaya dari semua perangkat node sensor. Data-data tersebut selanjutnya dikirimkan ke data center untuk pengolahan dan presentasi data lanjutan.

3. Pusat Data

Pusat data berperan untuk mengumpulkan, menyimpan dan mengolah data hasil pengamatan parameter fisik air kolam. Data yang sudah disimpan dan diolah selanjutnya dapat diakses oleh peternak ikan lewat sebuah aplikasi berbasis web.

\section{IMPLEMENTASI SISTEM}

Pada bagian ini akan dijelaskan mengenai implementasi dari komponen-komponen penyusun sistem.

\subsection{Implementasi Perangkat Node Sensor}

Seperti yang telah dipaparkan pada Bab 5, perangakat node sensor memiliki peranan penting untuk mengakuisisi data kondisi fisik air meliputi $\mathrm{pH}$, oksigen terlarut, suhu dan kekeruhan air. Data tersebut selanjutnya dikirimkan ke perangkat gateway menggunakan modul komunikasi LoRa.

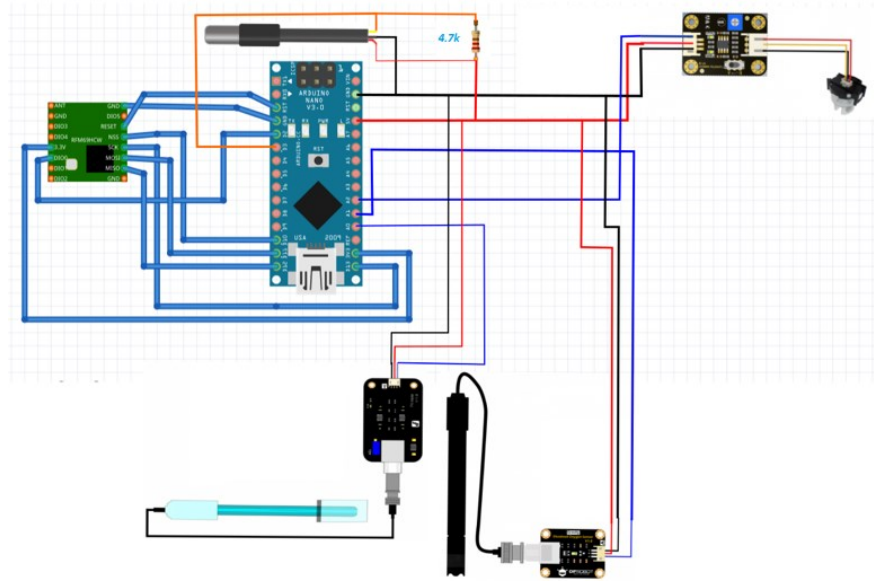

Gambar 6.1 Rangkaian Skematik Node Sensor

Untuk memenuhi kebutuhan fungsional di atas, peneliti merancang rangkaian skematik dari perangkat node sensor seperti ditunjukkan pada Gambar 6.1. Secara umum, perangkat node sensor terdiri atas 3 bagian yaitu komponen sensor, mikroprosesor dan modul komunikasi LoRa.

Komponen sensor berperan untuk melakukan persepsi terhadap kondisi fisik air yang meliputi empat parameter yaitu tingkat keasaman $(\mathrm{pH})$, oksigen terlarut, suhu dan tingkat kekeruhan. Untuk memenuhi kebutuhan tersebut, peneliti memanfaatkan beberapa jenis sensor, antara lain: 
1. DFDuino Gravity Dissolved Oxygen Sensor untuk mengukur kadar oksigen terlarut dalam air.

2. DS18B20 Waterproof Water Temperature Sensor untuk mengukur suhu air.

3. DFRobot $p H$ Meter Kit untuk mengukur kadar keasaman air.

4. Turbidity Sensor untuk mengukur tingkat kekeruhan air.

Data hasil pembacaan dari sensor-sensor tersebut kemudian diolah dan diakuisisi oleh perangkat mikroprosesor berbasis Arduino Nano. Selanjutnya, data sensor dikirim ke perangkat gateway menggunakan modul komunikasi HopeRF Wireless LoRa dengan frekuensi $433 \mathrm{Mhz}$ seperti ditunjukkan pada Gambar 6.2.

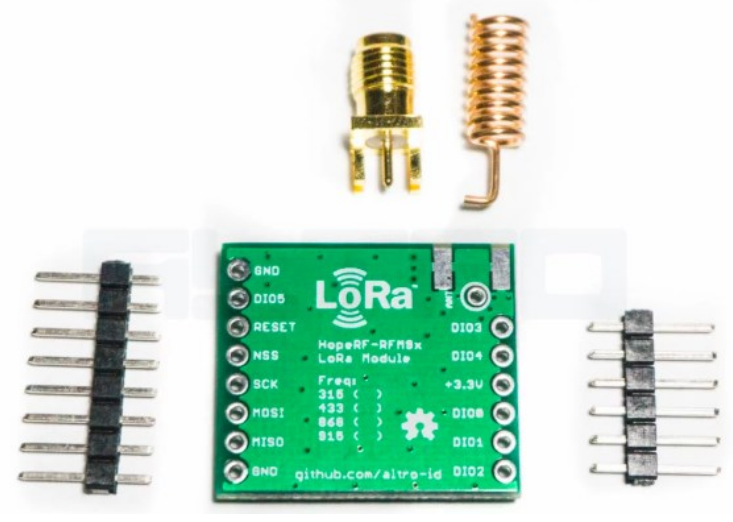

Gambar 6.2 Modul Komunikasi HopeRF LoRa 433 Mhz

\subsection{Implementasi Perangkat Gateway}

Data yang diolah oleh berbagai perangkat node sensor selanjutnya dikirimkan ke perangkat gateway untuk diagregasi sebelum dikirimkan ke pusat data. Dalam konteks komunikasi, perangkat ini berperan sebagai perantara antara perangkat node sensor di kolam dengan pusat data.

Gambar 6.3 menunjukkan rangkaian skematik dari perangkat gateway yang diusulkan. Secara umum, perangkat ini terdiri atas dua bagian utama yaitu perangkat minikomputer berbasis Raspberry Pi yang dilengkapi dengan modul LoRa untuk berkomunikasi dengan node sensor dan modul IEEE $802.11 \mathrm{~b} / \mathrm{g} / \mathrm{n}$ untuk berkomunikasi dengan pusat data.

Setelah menerima data dari perangkat node sensor, gateway membaca payload data dan mentranslasinya menjadi data berformat JSON untuk kemudian dikirimkan ke pusat data menggunakan protokol Restful Webservice.

\subsection{Implementasi Pusat Data}

Bagian pusat data berperan untuk menerima, data sensor untuk selanjutnya disimpan secara permanen dan diolah sesuai kebutuhan pengguna seperti melihat pola berapa lama kondisi air dapat dikatakan baik untuk budidaya ikan tertentu (menentukan waktu pergantian air). Secara umum, komponen pusat data yang dikembangkan terdiri atas komponen komunikasi, komponen security dan komponen manajemen data.

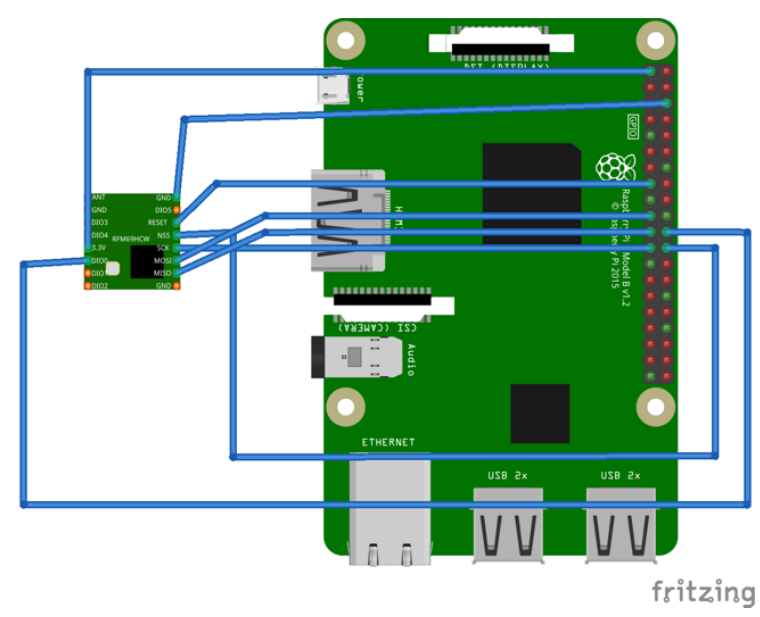

Gambar 6.3 Rangkaian Skematik Perangkat Gateway

Komponen komunikasi berperan untuk menyediakan antar muka komunikasi menggunakan protokol Restful Webservice. Setelah diterima oleh komponen komunikasi, data selanjutnya disimpan dalam sebuah basis data terdistribusi. Pada penelitian ini, peneliti memanfaatkan perangkat lunak MongoDB.

\section{PENGUJIAN DAN ANALISIS}

Pada penelitian ini dilakukan dua penelitian yaitu pengujian fungsionalitas dan pengujian kinerja. Pengujian fungsionalitas dilakukan untuk melihat bagaimana sistem merespon ketika terjadi perubahan pada lingkungan eksternal. Pengujian dilakukan untuk menguji fungsi semua sensor yang terhubung ke perangkat Arduino. Sensor yang terhubung ke Arduino digunakan untuk mendapatkan beberapa parameter meliputi.

- PH air

- Tingkat kekeruhan air

- Kadar oksigen dalam air, dan

- Temperatur

Pengujian dilakukan ke kolam yang kondisinya baru diganti airnya untuk merepresentasikan jenis air jernih dan kemudian polutan eksternal(misal:tanah dan sampah daun kering) ditambahkan sehingga kondisi air menjadi keruh. Pada penelitian ini tidak semua jenis polutan (polutan internal) diuji, karena fokus melihat fungsional sensor mampu merespon perubahan kondisi air. Sehingga polutan eksternal sudah cukup mewakili dan memang dapat mengubah kondisi air.

Hasil pengujian menunjukkan bahwa sistem telah mampu menangkap atau merespon perubahan yang terjadi pada air kolam. Pada Gambar 7.1 menunjukkan perbedaan hasil monitoring PH pada air jernih dan keruh. Pada Gambar 7.1 dapat dilihat 
bahwa pada air keruh memberikan respon dengan naiknya nilai PH. Hal ini dapat diakibatkan karena $\mathrm{PH}$ polutan eksternal, seperti tanah yang dimasukkan, bersifat basah.

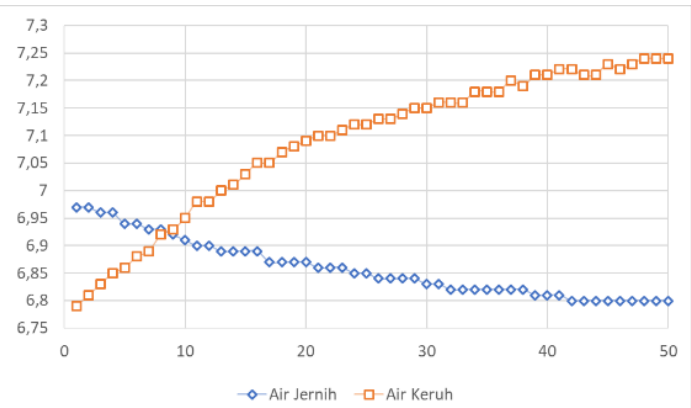

Gambar 7.1. Hasil Monitoring PH pada Air Jernih dan Keruh

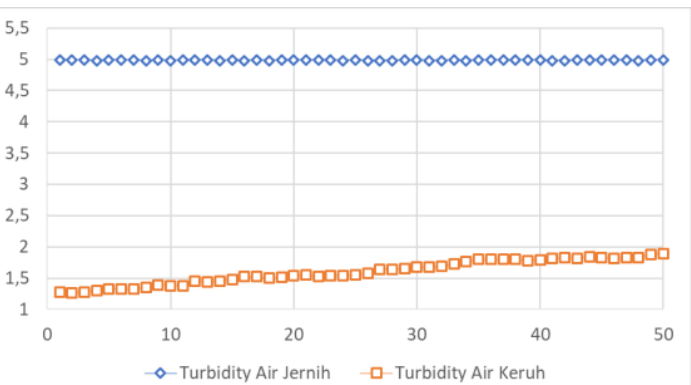

Gambar 7.2. Hasil Monitoring Turbidity pada Air Jernih dan Keruh

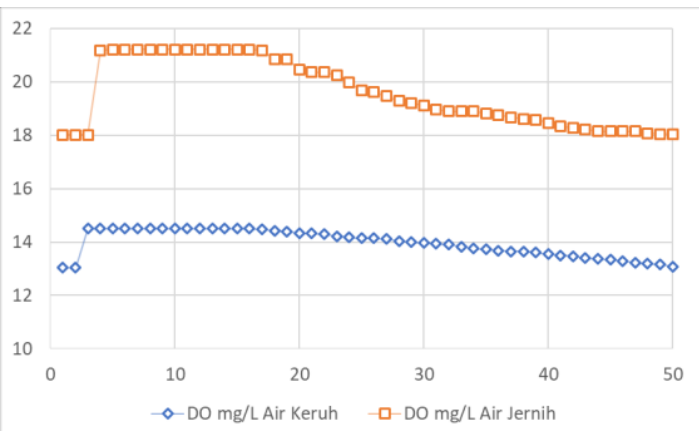

Gambar 7.3. Hasil Monitoring Oksigen Terlarut (DO)pada Air Jernih dan Keruh

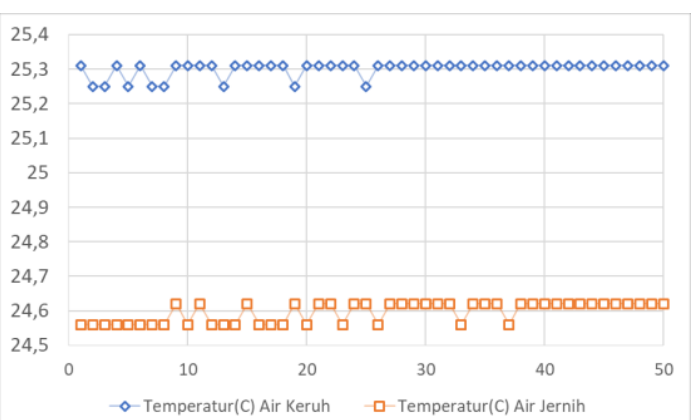

Gambar 7.4. Hasil Monitoring Temperatur(C) pada Air Jernih dan Keruh

Pengujian tingkat kejernihan air ditunjukkan pada Gambar 7.2. Turbidity Sensor menghasilkan output berupa besaran analog voltase(v). Semakin tinggi voltase yang dihasilkan maka semakin jernih kondisi air(dfrobot, 2017). Air yang keruh menunjukkan adanya objek lain yang terkandung dalam air.

Gambar 7.3 merupakan kadar oksigen terlarut yang diperoleh dari DFDuino Gravity Dissolved Oxygen Sensor. Hasil tersebut juga menunjukkan bahwa sistem berhasil merespons adanya perubahan kadar oksigen dalam air. Begitu juga hasil monitoring temperatur air, pada Gambar 7.4, yang menunjukkan bahwa sensor dapat merespons perubahan lingkungan meskipun kurang dari 1 derajat celcius.

Selanjutnya dilakukan pengujian kinerja protokol LoRa. Skenario pengujian ditujukan untuk melihat pengaruh jarak dan besar paket yang dikirimkan terhadap parameter delay dan packet loss. Pada Gambar 7.5 menunjukkan pengaruh jarak dan juga besar paket terhadap delay pengiriman paket. Hasil tersebut merupakan rata-rata delay pengiriman 100 paket untuk setiap ukuran paket yaitu 82, 157, 217 dan 251 Bytes. Pada Gambar tersebut ditunjukkan semakin besar paket mempengaruhi peningkatan nilai delay yang cukup tajam. Pada LoRa juga memiliki batasan untuk paket(header dan Payload) yang dikirimkan tidak melebihi 255 Bytes.

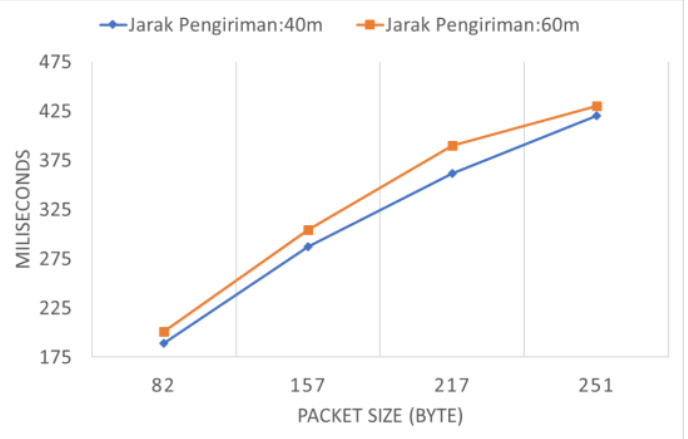

Gambar 7.5. Delay pengiriman Packet pada Penggunaan LoRa

Meskipun pengaruh jarak terhadap delay tedak terlalu signifikan namun jika dilihat pada Gambar 7.6, jarak memiliki pengaruh besar terhadap packet loss. Pada jarak 40 meter packet loss yang terjadi sebanyak 7,8\% dari total 400 paket yang dikirimkan. Ketika jarak dinaikkan menjadi $60 \%$, peningkatan packet loss mencapai empat kali lipat yaitu sebesar 41,125\%.

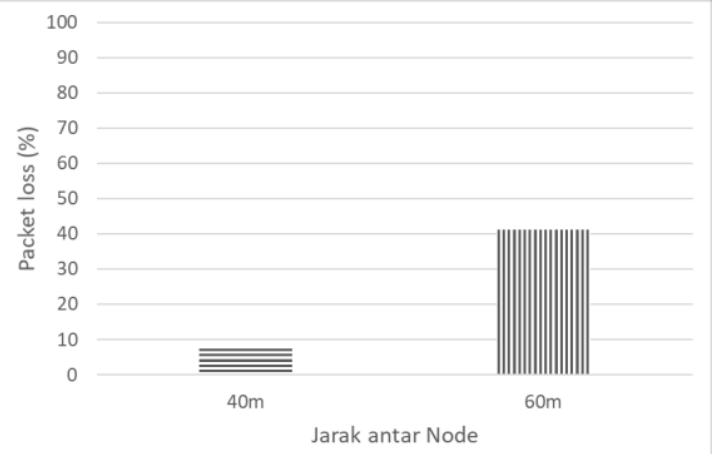

Gambar 7.6. Packet loss pada Pengiriman 400 Paket dengan Menggunakan LoRa 


\section{KESIMPULAN}

Pada penelitian ini telah dibangun sebuah sistem pemantauan kondisi air kolam budidaya ikan. Kondisi air yang dipantau antara lain adalah, tingkat kejernihan, $\mathrm{PH}$, kadar oksigen terlarut dan temperatur. Hasil pengujian fungsionalitas menunjukkan bahwa sistem yang dibangun mampu memberikan data dan merespons setiap perubahan pada lingkungan yang dipantau. Hasil pengujian kinerja LoRa menunjukkan bahwa jarak pengiriman mempengaruhi delay dengan nilai yang tidak signifikan. Besar paketlah yang mempengaruhi naiknya nilai delay secara signifikan. Namun untuk parameter packet loss, jarak pengiriman sangat mempengaruhi hasilnya. Ditunjukkan peningkatan lebih dari empat kali lipat pada jarak pengiriman 60 meter, yang sebelumnya berjarak $40 \mathrm{~m}$.

\section{DAFTAR PUSTAKA}

PHILIPS, M., HENRIKSON, VAN TRAN, DKK. 2015. Menjelajahi Masa Depan Perikanan Budidaya Indonesia. Gordon and Betty Moore Foundation.

TIM PENYUSUN DIREKTORAT JENDERAL PERIKANAN BUDIDAYA. Laporan Kinerja tahun 2016. Direktorat Jenderal Perikanan Budidaya, Kementrian Kelautan dan Perikanan.

MINGGAWATI, SAPTONO. Parameter Kualitas Air untuk Budidaya Ikan Patin (Pangasius pangasius) di Karamba Sungai Kahayan, Kota Palangka Raya. 2012. Jurnal Ilmu Hewani Tropika Vol. 1, No.1, Juni 2012.

MQTT Version 3.1.1 [WWW Document], n.d. URL http://docs.oasis-

open.org/mqtt/mqtt/v3.1.1/os/mqtt-v3.1.1os.html (accessed 3.20.17).

STALLINGS, W., 2010. Computer Organization And Architecture Designing For Performance. london: Prentice Hall.

WEISER, M., GOLD, R. \& GROWN, J. S., 1999. The origins of ubiquitous computing research at PARC in the late 1980s. IBM SYSTEMS JOURNAL, 38(4), pp. 693-696.

AMRON, KASYFUL, DKK. "Information and Data Distribution System for Rural Areas of Indonesia." Journal of Information Technology and Computer Science 1.1 (2016): 44-52.

ENSOR, I. (2004) "Wireless Sensor Networks," Communications of the ACM, 47(6), hal. 53-57. doi: 10.1016/S1389-1286(03)003517.

AL QALIT, FARDIAN FARDIAN, AULIA RAHMAN. Rancang Bangun Prototipe Pemantauan Kadar pH dan Kontrol Suhu Serta Pemberian Pakan Otomatis pada
Budidaya Ikan Lele Sangkuriang Berbasis IoT. Jurnal Karya Ilmiah Mahasiswa Teknik Elektro Universitas Syah Kuala. Vol. 2, No.3 tahun 2017.

RASHMI SHARAN SINHA, YIQIAO WEI, SEUNG-HOON HWANG, 2017. A survey on LPWA technology: LoRa and NB-IoT. ScienceDirect, CT Express 3 (2017) 14-21.

POOLE, I., 2017. LoRa Wireless for M2M \& IoT. [Online] Available at: http://www.radioelectronics.com/info/wireless/lora/basicstut orial.php [Diakses 10 Februari 2018]

RIP UB, TIM PENYUSUN, "Rencana Induk Penelitian Universitas Brawijaya Tahun 2016-2020”. Universitas Brawijaya. Oktober 2016. 
Halaman ini segaja dikosongkan 